\title{
ERICO VERISSIMO E MANOELITO DE ORNELLAS: RELAÇÕES LITERÁRIAS EM EPÍSTOLAS
}

\author{
Erico Verissimo and Manoelito de Ornellas: literary relations in epistles
}

\author{
Maria Eunice Moreira* \\ Fábio Varela Nascimento** \\ Pontifícia Universidade Católica do Rio Grande do Sul
}

\begin{abstract}
Resumo: Este artigo enfoca um conjunto de cartas enviadas por Erico Verissimo a Manoelito de Ornellas, preservadas no Acervo Literário de Manoelito de Ornellas, abrigado no DELFOS - Espaço de Documentação e Memória Cultural da Pontifícia Universidade Católica do Rio Grande do Sul, para analisar a correspondência trocada entre o autor de $O$ tempo e o vento e o crítico, poeta, romancista e criador da tese da origem hispânica do gaúcho platino. As quatro cartas destacadas aqui foram enviadas por Erico entre novembro de 1943 e abril de 1944. Nesse período, Erico Verissimo encontrava-se nos Estados Unidos a convite do Departamento Americano de Estado e proferiu conferências sobre literatura brasileira na Universidade de Berkeley, na Califórnia - dessas conferências resultou o livro Breve história da literatura brasileira. Manoelito de Ornelas, por sua vez, estava em Porto Alegre, exercendo funções públicas. As cartas enviadas por Erico revelam questões pessoais, profissionais, dúvidas como escritor, preocupações com a recepção de sua obra e o processo de escrita das conferências que compuseram Breve história da literatura brasileira.
\end{abstract}

Palavras-chave: Erico Verissimo. Manoelito de Ornellas. Correspondência.

Abstract: This paper focuses on a set of letters sent by Erico Verissimo to Manoelito de Ornellas, preserved in the Manoelito de Ornellas Literary Collection, housed in DELFOS Espaço de Documentação e Memória Cultural in Pontifícia Universidade Católica do Rio Grande do Sul, to analyze the correspondence exchanged between the author of $O$ tempo e $o$ vento and the critic, poet, novelist and creator of the thesis of the Hispanic origin of the platinum

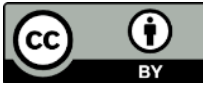

Esta obra está licenciada sob uma Creative Commons - Atribuição 4.0

\footnotetext{
* Professora titular da Escola de Humanidades - Letras da Pontifícia Universidade Católica do Rio Grande do Sul, Doutora em Lingüística e Letras (Teoria Literária) pela Pontifícia Universidade Católica do Rio Grande do Sul (1989). Coordenadora do Curso de Especialização em Literatura Brasileira da PUCRS. E-mail: maria.eunice@pucrs.br.
}

(iD https://orcid.org/0000-0003-1019-8519

** Doutor (2018) em Teoria da Literatura na Pontifícia Universidade Católica do Rio Grande do Sul, com bolsa CNPq. E-mail: fv.nasci@gmail.com.

iD https://orcid.org/0000-0002-8970-3161 
gaucho. The four letters outlined here were sent by Erico between November 1943 and April 1944. During this period, Erico Verissimo was in the United States at the invitation of the US Department of State and lectured about Brazilian literature at the University of Berkeley - from these conferences resulted the book Breve história da literatura brasileira. Manoelito de Ornelas, in turn, was in Porto Alegre, exercising public functions. The letters sent by Erico reveal personal, professional questions, doubts as a writer, concerns about the reception of his work and the writing process of the conferences that composed Breve história da literatura brasileira.

Keywords: Erico Verissimo. Manoelito de Ornellas. Correspondence.

Recebido em: 09/06/2018

Aceito em: 10/07/2018

Com uma carta pode acontecer

Que qualquer mentira venha a ser verdade...

Mário Quintana (2012), "Carta desesperada”, Apontamentos de história sobrenatural

Mário Quintana afirmou, certa vez, que com uma carta podia acontecer que uma mentira viesse a ser verdade, numa óbvia ironia com a palavra escrita e fixada no papel e sua relação com a realidade, ou pelo menos, com a realidade do missivista. Não obstante essa irônica frase do poeta gaúcho, as cartas trocadas entre escritores têm sido, atualmente, fonte inesgotável para o conhecimento das relações literárias, desvendamento do pensamento estético de autores e revelação, muitas vezes, de seus comentários críticos sobre sua própria obra ou sobre a produção de seus pares.

Entre "mentiras" e "verdades", as cartas permitem não só acessar a intimidade de autores, mas também revelar as preocupações e interesses de intelectuais e de suas circunstâncias pessoais e profissionais. Cartas são fontes primárias em arquivos literários, que merecem ser trazidas à luz, uma vez que possibilitam a reflexão sobre a personalidade do missivista e sua função para a construção da história da cultura e da literatura.

Voltado para a potencialidade que emerge de tais fontes, este artigo enfoca um conjunto de cartas enviadas por Erico Verissimo a Manoelito de Ornellas, preservadas no Acervo Literário de Manoelito de Ornellas, abrigado no DELFOS - Espaço de Documentação e Memória Cultural da Pontifícia Universidade Católica do Rio Grande do Sul, para analisar a correspondência trocada entre o autor de $O$ tempo e o vento e o crítico e criador da tese da origem hispânica do gaúcho platino. A convite da Organização dos Estados Americanos (OEA), Erico Verissimo encontrava-se nos Estados Unidos, país em que proferiu conferências das quais resultaram uma história da literatura brasileira, e sua correspondência com o amigo e colega autor de romances, ensaísta e professor de literatura, que, na época, estava em Porto Alegre revela questões pessoais, profissionais, dúvidas como escritor, preocupações com a recepção de sua obra e a origem da história da literatura que escreveu em inglês, sob o título Brazilian Literature: an outline, mais tarde traduzida sob o título de Breve história da literatura brasileira. 


\section{As cartas}

A correspondência entre Erico Verissimo (1905-1975) e Manoelito de Ornellas (19031969), arquivada no DELFOS, estende-se de 1928 a 1962, constituindo um conjunto de cerca de trinta e seis cartas, algumas sem data e outras sem indicação do local da escrita, todas elas de autoria de Erico. Não foram localizadas, nesse conjunto, até o presente momento, as respostas de Manoelito ao amigo viajante. Essa correspondência está alicerçada em uma sólida amizade, que começou quando os dois ainda trabalhavam como farmacêuticos e alimentavam aspirações literárias. Provenientes de duas regiões diferentes do Rio Grande do Sul - Erico Verissimo nasceu em Cruz Alta, no noroeste do Estado, e Manoelito de Ornellas era originário de Itaqui, município do sudoeste gaúcho, na fronteira com a Argentina -, os dois "guris" conheceram-se na terra do primeiro. Em Solo de clarineta, obra de memórias, Erico lembrou do encontro:

A primeira vez em que vi Manoelito de Ornellas foi numa tarde de inverno de 1928. Atravessava ele a praça principal de Cruz Alta, envergando um sobretudo preto trespassado, de corte elegante, com gola de veludo, a bela cabeça coberta por um chapéu gelô claro. Caminhava teso, com passadas firmes e cadenciadas, o queixo erguido. Via-se logo que não era uma pessoa qualquer, mas uma personalidade. (VERISSIMO, 1974, p. 219)

Em 1928, essa "personalidade" vivia em Tupanciretã, cidade vizinha a Cruz Alta, sustentava-se com as rendas vindas de uma farmácia e saboreava as experiências de ser um autor estreante, pois, naquele ano, publicara Rodeio de estrelas, livro de poesias. Pouco tempo depois de se aproximarem, o itaquiense ajudou o amigo a chegar às páginas da recém-lançada Revista do Globo. Manoelito enviou os originais de "Ladrão de gado" para Mansueto Bernardi, então diretor da revista, o conto foi publicado e as portas da Globo se abriram para Erico. Tempos depois, em Porto Alegre, local para onde os dois se mudaram na década de 1930 a fim de dar andamento à vida profissional e literária, as relações se fortificaram. O vínculo e a comunicação entre eles só arrefeceram em meados dos anos 1960, em consequência de algum comentário de Erico sobre a obra ou sobre determinada atitude de Manoelito. Não estão bem esclarecidas as causas do desentendimento; o certo, porém, é que o episódio ocasionou a quebra da amizade entre os dois e, por não ter obtido o perdão do amigo, Erico carregou essa mágoa até a morte.

Manoelito foi uma espécie de alter ego de Erico, que lhe confiou suas dúvidas, inquietações, problemas de escritura, e suas fragilidades de escritor. Circulavam entre eles comentários sobre questões da vida pessoal, sobre personalidades com quem conviviam, sobre temas relacionados à Associação Riograndense de Imprensa (ARI) - em 1938 Manoelito sucedeu a Erico na presidência da entidade - e sobre as peculiaridades da vida literária, numa interlocução objetiva e franca, só concretizada entre amigos de total confiança.

É possível observar nas cartas trocadas entre eles os comentários pessoais de Erico sobre a família de Manoelito, composta por Lucy, a mulher, e Lília, a filha, uma adolescente com pouco menos de 15 anos; as interferências de Mafalda, esposa de Erico; as informações de Erico 
a Manoelito sobre os namoros de sua filha Clarissa, ou mesmo o interesse do futuro escritor Luiz Fernando Verissimo por jazz e viagens para assistir a um e a outro concerto de música, quando moravam nos Estados Unidos.

Erico residiu por três ocasiões nos Estados Unidos da América. Nas duas primeiras, foi a convite do Departamento de Estado Americano, aproveitando as oportunidades abertas pela política da boa vizinhança de Franklin Delano Roosevelt. Em 1941 a estada foi solitária, dividida entre diversas conferências, durou três meses e resultou em uma narrativa de viagem - Gato preto em campo de neve (1941). Já a segunda experiência, relatada em $A$ volta do gato preto (1946), foi vivida ao lado da mulher e dos filhos e se desenvolveu em um período mais longo, de 1943 a 1945. Nesses anos, Erico ministrou aulas na Universidade de Berkeley, na Califórnia. Espécie de autoexílio, a segunda viagem ocorreu nos últimos tempos da ditadura de Getúlio Vargas e depois da publicação de $O$ resto é silêncio, romance criticado por parte do clero, especialmente pelo jesuíta Leonardo Fritzen, docente do Colégio Anchieta que classificou o livro de imoral. O clima autoritário e a vigilância dos guardiões da moralidade fizeram com que Erico partisse para o exterior "para respirar ares mais livres e descansar de toda aquela choldra estado-novista" (VERISSIMO, 1964, p. 74). O terceiro momento de residência nos Estados Unidos deu-se entre 1953 e 1956, quando aceitou o convite para dirigir o Departamento de Assuntos Culturais da União Pan-Americana, na secretaria da OEA.

Do conjunto de trinta e seis cartas, quatro datadas de 1943 e 1944 são privilegiadas neste estudo. Na época, Manoelito de Ornellas estava em Porto Alegre e, após dois anos à frente da Biblioteca Pública do Estado, ele desempenhava as funções de diretor do Departamento de Estadual Imprensa e Propaganda (DEIP). Erico, por sua vez, estava na sua segunda temporada norte-americana. Naquela ocasião, ele proferiu uma série de conferências que foram posteriormente reunidas, originando o livro já mencionado, Brazilian literature: an outline, editado pela MacMillan Company, em 1945, e depois reeditado pela Greenwood Press, em 1969. O work in progress foi sendo pouco a pouco comentado com Manoelito, embora Erico não pretendesse, de início, transformar as conferências em livro.

A primeira dessas cartas foi escrita em 10 de novembro de $1943^{1}$, dois meses depois da chegada de Erico à Califórnia. Comenta o escritor que acabou de se estabelecer e que o curso que ministra no Mills College vai bem, reunindo mais de trinta alunos interessados em assuntos brasileiros. A recepção positiva dessas conferências pode ser avaliada pelo convite que já recebeu para dar um curso de verão sobre o Brasil. Nessa fase, as conferências sobre literatura brasileira ainda não iniciaram, pois estão previstas para janeiro e fevereiro de 1944.

Nessa primeira carta, escrita talvez sob o impacto da mudança e das adaptações que exigiam a nova vida, Erico não foi muito detalhista em relação a seus compromissos e, em especial, às conferências que ministraria sobre o Brasil e que constituíam seu compromisso maior. Em nova carta que enviou ao amigo que ficara em Porto Alegre, datada de 4 de janeiro

\footnotetext{
${ }^{1}$ A carta é composta por 1 folha, está datilografada e assinada com caneta preta. Seu número de localização é: MOR COR 534.
}

Anu. Lit., Florianópolis, v. 23, n. 2, p. 25-33, 2018. ISSNe 2175-7917 
de $1944^{2}$, oferece maiores informações sobre as atividades docentes e os deslocamentos frequentes - três vezes por semana viajava "ao outro lado da baía" para dar aulas. O curso que ministrava sobre literatura brasileira, disse ele, exigiam muito preparo e suas conferências sobre a matéria, a começarem em breve, exigiriam mais ainda, pois seriam ministradas em língua inglesa. Erico relatou, então, como preparara seu plano de trabalho e suas pesquisas em torno do assunto, prevendo a seguinte distribuição da matéria: $50 \%$ seriam dedicados à história política, social e econômica do Brasil; $40 \%$ à literatura pura e $10 \%$ à vida anedótica do Brasil. Sua proposta era a de sintetizar os fatos políticos e econômicos para explicar os literários. A uma assistência que desconhecia o país do qual ele falava e, em especial, sua literatura, o método parecia ter validade, pois se tratava de uma abordagem de ordem mais cultural do que propriamente literária. Por outro lado, esse esquema ou essa metodologia, segundo o próprio autor, alterava a usual rotina docente, pela qual os professores americanos, especialistas em seus temas, eximiam-se de abordar outros aspectos, limitando-se apenas aos de sua especialização.

É interessante a preocupação de Erico com a possível recepção de suas conferências, valendo-se não apenas de recursos distintos dos adotados pelos demais professores, mas também invocando estratégias para manter a atenção dos ouvintes, perceptível na intenção de dispor de histórias anedóticas ou mais leves sobre o Brasil para entremear nas conferências. No "Prefácio" à Breve história da literatura brasileira, a edição organizada das conferências, confirma que a estratégia da "história ou anedota retirada de algum romance, conto ou poema da literatura brasileira" (VERISSIMO, 1995, p. 13), visava a evitar que "a plateia adormecesse, embalada pelo zunzum da minha voz, enquanto eu repetia monotonamente nomes de autores ou títulos de livros numa língua que lhe era estranha" (VERISSIMO, 1995, p. 13). As conferências foram escritas para serem lidas e, por certo, a interrupção de leitura pela introdução de um chiste pretendia também manter a atenção dos alunos e dos professores que assistiam a essas aulas. Já prevalecia aqui a técnica do "contador de histórias", epíteto com que Erico sempre se identificou, sobre o do conferencista severo.

Uma das histórias irônicas que Erico registrou encontra-se no capítulo "Sim, mas serpentes e escravos também" e remete ao famoso escritor Machado de Assis, também ele um homem sisudo e pouco avesso a brincadeiras. Para esclarecer a ironia machadiana, Erico narra a seguinte historinha: "Certo dia, durante uma festa, uma senhora tagarela dirigiu-se a ele sorridente: 'Ora, senhor Machado, disseram-me que tinha uma terrível gagueira. Mas o senhor fala bastante bem. Não é tão má como dizem'. O rosto do escritor era uma máscara de pedra quando respondeu: 'Calúnias, cara madame, apenas calúnias. Disseram-me que a senhora era muito tola, e agora vejo que não é tão tola, como dizem"” (VERISSIMO, 1995, p. 13).

$\mathrm{Na}$ carta seguinte, escrita em 17 de fevereiro de $1944^{3}$, Erico parece sentir-se mais

\footnotetext{
${ }^{2}$ A carta é composta por 2 folhas, está datilografada e assinada com caneta preta. Seu número de localização é: MOR COR 535.

${ }^{3}$ A carta é composta por 2 folhas, está datilografada e assinada com caneta preta. Seu número de localização é: MOR COR 568.
}

Anu. Lit., Florianópolis, v. 23, n. 2, p. 25-33, 2018. ISSNe 2175-7917 
"solto" e também mais propício a falar de si e dos outros. O início da carta já é aliviado pelas alusões à paisagem local e ao "ao ar parado, perfumado, de um frio seco e agradável", mostrando que o missivista confundia-se com o narrador dos romances. A abertura da carta remete a uma das cenas de Clarissa (1933), primeiro romance publicado por Erico: Porto Alegre apresentava uma manhã colorida e perfumada. $\mathrm{O}$ espaço americano, que serviu para iniciar a mensagem a Manoelito, é o lugar onde Erico se situa para dar notícias de caráter pessoal ao amigo. Sua família, já bem ajustada aos costumes americanos, desfruta dos passeios ao ar livre, como descreve o narrador-missivista: "circundamos o lago onde cisnes brancos e pretos brincavam de soneto parnasiano. Longe azulavam montanhas vagamente reminiscentes de Petrópolis. Marrecos e gaivotas confraternizavam ao sol. O cheiro dos pinheiros e dos eucaliptos embalsamavam o ar, como em qualquer romance barato desses que se passam no campo".

Três expressões chamam a atenção nessa descrição: a) a invocação de uma forma e de um estilo literários para caracterizar a paisagem; b) a referência a Petrópolis, bairro onde Erico residia em Porto Alegre, com ruas onduladas como as coxilhas gaúchas; c) a relação entre romance barato e o campo, reportando-se à sua própria obra, entendida às vezes como "adocicada" pelo tratamento dispensado a tipos sem o devido vigor dramático. É o próprio escritor quem reconhece que "Caminhos cruzados, O resto é silêncio e Um lugar ao sol são livros cujos resultados foram um tanto aguados, sem profundidade, talvez por causa mesmo de sua enorme superfície". No entanto, quando comenta a avaliação que Ivan Pedro de Martins, autor de Fronteira agreste (1944), romance com forte crítica social, faz de sua obra, considerando-o "um escritor suave para moças", isso o atinge profundamente. Cada um, segundo ele, escreve de acordo com suas possibilidades, "com suas glândulas, com seu passado, com sua experiência e com seus sonhos". Mesmo assim, essa opinião severa não impediu Erico de recomendar à Livraria do Globo a publicação do livro de Ivan Pedro de Martins nem de se opor à apreensão dos seus exemplares quando Ângelo Guido, censor ligado ao DEIP, declarou que Fronteira agreste "feria a moral e os bons costumes pelas cruas cenas de sexo impressas no romance" (HOHLFELDT, 1998, p. 26).

Entre fevereiro e abril, a correspondência sofreu um pequeno interregno. Erico voltou a escrever a seu amigo em 14 de abril de $1944^{4}$, depois que o ciclo de conferências se encerrara e talvez por isso essa seja a mais longa carta que escreve nesse período de afastamento. Ao retomar o assunto das conferências, confirma que o resultado foi muito positivo e que a editora MacMillan, de Nova York - que já publicara, em 1942, a tradução de Caminhos cruzados -, mostrou-se disposta a ler as seis conferências sobre Literatura Brasileira, com vistas à eventual edição. Para enviar à avaliação da editora, está trabalhando nos textos, retirando os vestígios de conferência, ampliando alguns capítulos, incluindo um novo sobre os últimos anos da literatura no Brasil e acrescentando uma relação de livros representativos do país. No "Prefácio" à edição brasileira, esclarece que tratou dos "últimos vinte anos da vida literária brasileira"

\footnotetext{
${ }^{4}$ A carta é composta por 3 folhas, está datilografada e assinada com caneta preta. Seu número de localização é: MOR COR 567.
}

Anu. Lit., Florianópolis, v. 23, n. 2, p. 25-33, 2018. ISSNe 2175-7917 
(VERISSIMO, 1995, p. 13), embora não dispusesse de "nenhuma obra de referência, qualquer que fosse" (VERISSIMO, 1995, p. 13), para supri-lo de informações.

Novos convites chegaram a Erico e, em abril, quando escreveu a Manoelito, referiu-se especialmente a outra conferência que proferiu em encontro especial na Universidade, pela comemoração do Dia Pan-Americano. Nessa ocasião, Erico discursou para uma plateia de cinco mil pessoas, entre personalidades latino-americanas, professores universitários e alunos. Desse encontro, ele recortou a seguinte passagem para incluir na carta:

Tomemos muito cuidado, meus amigos, porque no meu país em quase todas as nações sul-americanas existe um grupo suficientemente estúpido para quererem fazer uma festa com trágicas sobras do banquete hitlerista. $\mathrm{O}$ fascismo tenta desesperadamente sobreviver à derrota do Eixo e para isso usará toda a sorte de disfarces. As ideias totalitárias já estão procurando refúgio em terras da América. Precisamos combater todas as formas de fascismo se quisermos preservar a paz neste hemisfério ${ }^{5}$.

Naqueles tempos de guerra, Erico partilhava com Manoelito o mesmo contexto histórico e expressava seus ideais políticos numa espécie de extravasamento pessoal sobre suas preferências ideológicas. Ao comunismo dos "cachaceiros, ele prefere o socialismo, embora reconheça que qualquer coisa que faça de diferente é taxado de comunismo", como ele desabafou. Sua ânsia era pela justiça social, tema pelo qual continuava a propugnar, apesar de distante do Brasil. Emergia daí o desejo de escrever um romance que expusesse melhor seu pensamento sobre os problemas sociais, que no Brasil se manifestavam na questão educacional e de saúde pública. Nessa mesma carta, Erico relatou que uma aluna perguntou-lhe sobre a ideologia de Mário Quintana, poeta pelo qual ficara fascinada após a conferência. De forma brincalhona, Erico respondeu que a posição ideológica de Mário era o "mundo da lua", deixando estupefata sua interlocutora, pelo modo como o olhou com a resposta.

O fato é que o tema da ideologia tornou-se recorrente e a imagem de Erico que deriva de suas observações é a de um sujeito que almeja ser coerente em todas as fases de sua vida e em todos os espaços por ele habitados. Pouco a pouco, carta a carta, vai construindo uma persona, definindo traços de comportamento, numa forma para favorecer a coesão dos laços de amizade com seu interlocutor, mas também para se construir como um sujeito que reclama e exige sua coerência em todas as fases de vida. Isso é possível?

Ao recolher a correspondência entre Carlos Drummond de Andrade e Alceu Amoroso Lima, Leandro Garcia Rodrigues destaca, no prefácio da obra Drummond \& Alceu, que as relações epistolares entre os escritores, nessa troca de cartas que vão e que vêm, "possibilita a compreensão de determinados estilos e intenções, determinadas obras e os caminhos de sua criação, bem como corrobora para a decifração de inúmeras problemáticas biográficas que envolvem o universo pessoal dos artistas”. (RODRIGUES, 2014, p. 25). É evidente - e de novo Leandro Garcia Rodrigues destaca - que "a correspondência dificilmente produz a ilusão de uniformidade de um retrato 'estático' dos interlocutores” (RODRIGUES, 2014, p. 12). Ao

\footnotetext{
${ }^{5}$ Essa citação foi retirada da carta de Erico Verissimo na qual ele transcreve uma passagem da conferência.
} 
contrário, a autorrepresentação modifica-se com o passar do tempo, pois o autor da carta é um sujeito em constante transformação.

Deixando de lado essas questões, ainda incipientes em virtude do corpus de análise reduzido, o fato é que Erico dá provas de sua performance como orador, performance por ele próprio reconhecida em sucessivas cartas a Manoelito e que parecem superar qualquer ideologia. A carta conta que novos encontros estão sendo programados, embora ele continue dizendo que não gosta de falar em público. Quase todas as semanas, o escritor tinha compromissos com palestras a grupos de estudantes, audiência com que mantinha um salutar intercâmbio. Ao final de abril de 1944, já havia agendado outro meeting para abordar o Brasil. O evento ocorreu no Museu de Arte de Oakland e a essa fala deu o político título "Boa vizinhança através da aproximação cultural”. Nesse Brasil múltiplo mostrado por Erico, vários são os aspectos enfocados: a gente, o ritmo de vida, as cenas provincianas, o Rio de Janeiro, chamando a atenção para a "colcha de retalhos" que constitui o país, aglutinado por um fator comum: "a milagrosa unidade de língua".

A par essas questões que dizem respeito especificamente à sua atuação enquanto represente brasileiro junto ao Departamento de Estado Americano, revela-se também outro Erico, uma outra persona, ligada à sua família e à cidade que deixou no Brasil, mas que é parte de seu ser: Porto Alegre. Para falar de Porto Alegre, concede a palavra à sua esposa. Segundo ele, Mafalda manifesta um sentimento muito curioso em relação à cidade que faz com que tenha saudades, mas não deseja voltar. O ambiente de fofocas, intrigas e falatórios que aí existe a coloca nessa posição instável. Somente no final da carta, Erico volta a utilizar a primeira pessoa, ao se referir à capital gaúcha, para expressamente assinalar que tudo passa pela mão do Arcebispo Dom João Becker e pela Associação de Professores Católicos, razão por que, também para ele, o retorno é um desgaste que tenta evitar, ao menos por enquanto. Apenas de um ponto ele tem saudades: dos verdadeiros amigos, entre os quais, com certeza, figura Manoelito de Ornellas.

Das cartas de Erico Verissimo, lidas através da correspondência com Manoelito de Ornellas, ressalta um sujeito que é "cuidadoso" no que escreve, mas que não deixa de criticar autores e obras do Brasil e projetar o retrato de um escritor, um contador de histórias, um sujeito que se mostra amigo dos amigos - e até dos inimigos - tentando assegurar a coerência no conjunto de suas atitudes.

Com cartas, pode acontecer que toda a mentira venha a ser verdade, mas também pode ocorrer que a verdade transforme-se numa grande mentira. Às cartas de Erico Verissimo a Manoelito de Ornelas pode ser transferida a mesma observação que Leandro Garcia Rodrigues aplica à correspondência entre dois outros intelectuais brasileiros - Carlos Drummond de Andrade e Alceu Amoroso Lima: "cartas repletas de possibilidades interpretativas e agentes de transformação do cânone da nossa própria história literária" (RODRIGUES, 2014, p. 25). Entre o público e o privado, a correspondência preenche várias lacunas, possibilitando a compreensão do trajeto de determinadas obras (história da literatura e romances, no caso de Erico), decifrações de intenções e relações no campo da literatura e elucidações (ou não) sobre o 
universo pessoal dos autores, enfim, de suas problemáticas biográficas.

Se as cartas são "pensamenteadas" (RODRIGUES, 2014, p. 24) ou não, usando a expressão de Mário de Andrade empregada numa carta a Manuel Bandeira, não se sabe, mas também elas atingem o campo do ficcional, exigindo, portanto, um sentido de decifração mais amplo e complexo por parte do hermeneuta. Cartas são "repletas de possibilidades interpretativas", como diz Leandro Garcia Rodrigues (2014, p. 24), e, por isso, podem afetar o cânone literário, trazendo à luz questões que se situam entre o público e o privado, entre o dito e o não dito, entre o exposto e o escondido. Cartas revelam o ouro lado do criador, muitas vezes o lado solar, em outras, o lado sombrio dos artistas e de suas criações. Com cartas pode acontecer que muita mentira venha a ser verdade, como disse o poeta do Rio Grande do Sul, mas - entre escritores e no domínio da escrita - muita verdade também não poderia ser uma "gostosa brincadeira"? Ou, quem sabe, as cartas, como os búzios, não mentem jamais?

\section{Referências}

HOHLFELDT, Antonio. Trilogia da campanha: Ivan Pedro de Martins e o Rio Grande Invisível. Porto Alegre: EDIPUCRS, 1998.

QUINTANA, Mario. Carta desesperada. Apontamentos de história sobrenatural. Rio de Janeiro: Objetiva, 2012, p. 174.

RODRIGUES, Leandro Garcia. (Org.). Drummond \& Alceu. Correspondência de Carlos Drummond de Andrade \& Alceu Amoroso Lima. Belo Horizonte: Editora UFMG, 2014. p. 25.

VERISSIMO, Erico. Breve história da literatura brasileira. São Paulo: Globo, 1995.

VERISSIMO, Erico. O escritor diante do espelho. Ficção completa. Rio de Janeiro: Aguilar, 1964. v. 1, p. 74.

VERISSIMO, Erico. Solo de clarineta - memórias I. Porto Alegre: Globo, 1974.

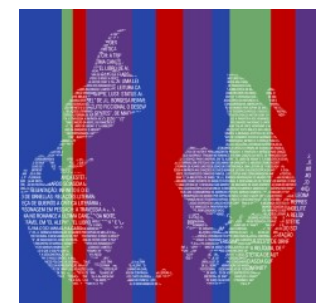

